\title{
Maternal and perinatal outcome in obstetric cholestasis- a prospective observational study
}

\author{
Ruma S. Anand*, Naghma Khan, Najma Malik, Vani Aditya, Reeta Singh
}

Department of Obstetrics and Gynecology, BRD Medical College, Gorakhpur, Uttar Pradesh, India

Received: 12 December 2020

Accepted: 13 January 2021

*Correspondence:

Dr. Ruma S. Anand,

E-mail: rumasarkaranand@gmail.com

Copyright: (C) the author(s), publisher and licensee Medip Academy. This is an open-access article distributed under the terms of the Creative Commons Attribution Non-Commercial License, which permits unrestricted non-commercial use, distribution, and reproduction in any medium, provided the original work is properly cited.

\begin{abstract}
Background: The objective of this study was to study the maternal and perinatal outcome of pregnancy complicated by obstetric cholestasis.

Methods: This prospective observational study included 80 cases, diagnosed as obstetric cholestasis on the basis of symptoms of persistent pruritus (generalized or localized), biochemical evidence of altered liver function test and excluding other liver and skin disorder. Medical treatment and active management (fetal surveillance and termination of pregnancy at 37-38 weeks) were offered to all. Maternal and perinatal outcome were studied.

Results: Incidence of obstetric cholestasis was 1.9\%. Majority of women (55\%) were primigravida and recurrence rate was $61.1 \%$ among multiparous women. Pruritus (generalized) was the cardinal symptoms in $90 \%$ patients and mostly (88.7\%) presented and diagnosed after 28 weeks i.e. in third trimester. A total of $43.7 \%$ women had caesarean section (CS) which was quite high incidence. Most common pregnancy complications included preterm labor (25\%), post-partum haemorrhage $(13.75 \%)$ and preterm premature rupture of membrane (11.25\%). Perinatal outcome revealed meconium aspiration (20\%), preterm birth (30\%), low birth weight (35\%), fetal distress $(18.75 \%)$ and intrauterine fetal death (2.5\%). 43.75\% neonates required NICU (Neonatal intensive care unit) admission. Serum transaminase levels tended to be higher in patients with poor perinatal outcome such as still birth, fetal distress and meconium stained amniotic fluid. LFT (liver function test) returned to normal in $95 \%$ of women and $100 \%$ women became symptom free after 6 weeks postpartum.

Conclusions: Obstetric cholestasis has an adverse effect on the fetal outcome and hence early diagnosis with careful clinical examination and biochemical testing is essential. Serum abnormality in liver function test (transaminases) tended to be higher in women with poor perinatal outcome.
\end{abstract}

Keywords: Obstetric cholestasis, Perinatal outcome, Pruritus

\section{INTRODUCTION}

Obstetric cholestasis also called as intrahepatic cholestasis, cholestatic hepatosis or icterus gravidarum is a unique and most common pregnancy related liver disorder occurring during the late second or third trimester of pregnancy. Hallmark symptom of obstetric cholestasis (OC) is pruritus in the absence of skin eruption or rashes. Most common site of pruritus is on palms and soles. Itching ranges from mild to debilitating and intense and is typically worse at night. The onset of pruritus often precedes biochemical derangement. ${ }^{1}$ It is a reversible disease as after the strip of the placenta, signs and symptoms of obstetric cholestasis disappear. ${ }^{2}$

The incidence of Intrahepatic cholestasis of pregnancy has been found to be variable, with $0.1-1.5 \%$ of the population of Central and Western Europe and North America, and $1.5-4 \%$ in Chile and Bolivia. ${ }^{3}$ The incidence of intrahepatic cholestasis of pregnancy among Indian women has been reported to be around 1\%.,

The pathogenesis of intrahepatic cholestasis of pregnancy, although not well defined, is thought to be 
multifactorial, including an environmental and genetic basis for disease. Alternative causes of itching and abnormal liver function test should be excluded. Post natal resolution of pruritus and abnormal liver function test should be confirmed to establish the diagnosis. ${ }^{6}$

Clinical importance of obstetric cholestasis lies in the potential fetal risks which may include spontaneous preterm birth, iatrogenic preterm birth and fetal death. There can also be maternal morbidity in association with intense pruritus and consequent sleep deprivation.

Our study aimed at determining the maternal and fetal outcome of pregnancy complicated by obstetric cholestasis.

\section{METHODS}

This prospective observational study included 80 cases of intra hepatic cholestasis, diagnosed and managed in department of obstetrics and gynecology, BRD medical college during the period between July 2018 and June 2019. Diagnosis of cholestasis of pregnancy was made on the basis of symptoms of persistent pruritus (generalized/ localized), biochemical evidence of altered liver function test and by excluding other liver and skin disorder. The upper end of the normal range in pregnancy was assumed to be $80 \%$ of the level quoted in nonpregnant women. ${ }^{6}$

Demographic data and complete history regarding personal, family, medical and drug history were taken. Obstetric profile like gravidity, past history of obstetric cholestasis, gestational age at the onset of pruritus, diagnosis of obstetric cholestasis and at the onset of spontaneous labor were noted. After diagnosis of obstetric cholestasis subjects were treated with ursodeoxycholic acid $20 \mathrm{mg} / \mathrm{kg} /$ day in divided doses. Once identified, monitoring of subjects included regular prenatal visits regarding nature and severity of pruritus.

Liver function test were repeated every 1 to 2 weeks interval. Fetal surveillance was done with daily maternal recordings of fetal movements, CTG or regular Doppler ultrasonography twice a weeks after 32 weeks of gestation. Any complications during pregnancy such as PPROM (preterm premature rupture of membrane), Preterm labor were noted. Women with 38 weeks of gestation were offered active management i.e. termination of pregnancy either by induction or by elective caesarean section (CS) if indicated. Mode of delivery, pregnancy outcome in spontaneous and induced group, results of liver function test, coagulation profile, maternal complications, perinatal outcome and postpartum resolution period were noted.

\section{Statistical analysis}

Result is presented in percentage. No statistical test was applied.

\section{RESULTS}

A total of 80 women with obstetrics cholestasis were recruited out of 4086 deliveries occurred during the study period. Hence the incidence of obstetric cholestasis in our institute was found to be $1.9 \%$. Most of the cases (43.75\%) occurred between 26-30 years. Maternal mean age in our study was 27.81 \pm 3.65 years (range 20-35 years). Larger number of women had rural background $(56.25 \%)$, educational level below $8^{\text {th }}$ standard $(71.25 \%)$ and belong to lower socio economic status (51.25\%) (Table 1).

Table 1: Demographic profile.

\begin{tabular}{|c|c|c|c|}
\hline \multicolumn{2}{|l|}{ Factors } & No. & Percentage \\
\hline \multirow{4}{*}{ Age } & $20-25$ & 29 & 36.25 \\
\hline & $26-30$ & 35 & 43.75 \\
\hline & $31-35$ & 14 & 17.5 \\
\hline & $>35$ & 2 & 2.5 \\
\hline \multirow{3}{*}{$\begin{array}{l}\text { Socio } \\
\text { economic } \\
\text { status }\end{array}$} & Upper & 3 & 3.75 \\
\hline & Middle & 36 & 45.0 \\
\hline & Lower & 41 & 51.25 \\
\hline \multirow{4}{*}{$\begin{array}{l}\text { Educational } \\
\text { level }\end{array}$} & Illiterate & 10 & 12.50 \\
\hline & Upto $8^{\text {th }}$ std. & 47 & 58.75 \\
\hline & $9^{\text {th }}-12^{\text {th }}$ std. & 18 & 22.50 \\
\hline & Graduate and above & 05 & 6.25 \\
\hline \multirow{2}{*}{ Background } & Rural & 45 & 56.25 \\
\hline & Urban & 35 & 43.75 \\
\hline
\end{tabular}

Majority of women with Obstetric cholestasis (55\%) were primigravida and among rest multiparous women $(45 \%), 61.1 \%$ women had prior history of obstetric cholestasis.

Generalised pruritus was the cardinal symptoms (90\%), most pronounced in palms and soles and worsen at night. Most of the women $(88.75 \%)$ presented and diagnosed as Obstetric cholestasis after 28 weeks. Out of total 80 cases, $45(56.25 \%)$ had spontaneous onset of labour, 15 $(18.75 \%)$ were induced and $20(25 \%)$ were decided for elective caesarean section. In spontaneous group 35 $(77.7 \%)$ had vaginal delivery and 10 (22.2\%) had emergency caesarean section. In induced group 10 $(66.6 \%)$ delivered vaginally and emergency caesarean section was done in $5(33.3 \%)$ patients (Table 2).

$70.25 \%$ patients had elevated Serum bilirubin. Majority of patients $(45 \%)$ had serum bilirubin level in the range of $0.9-1.6 \mathrm{mg} / \mathrm{dl}$. Total serum bilirubin rarely exceeds 4-5 $\mathrm{mg} / \mathrm{dl}$. Serum aminotransferase (ALT and AST) were elevated 2-20 folds above the normal ranges but none exceeded 600 IU/l. The value of ALP (alkaline phosphatase) were found to be raised in $67.5 \%$ patients from $400 \mathrm{IU} / 1$ to as high as $800 \mathrm{IU} / \mathrm{l}$ (Table 3). 
Table 2: Obstetric profile.

\begin{tabular}{|c|c|c|c|}
\hline Factor & & No. & Percentage \\
\hline \multirow{5}{*}{ Gravidity } & Primi & 44 & 55 \\
\hline & $2^{\text {nd }}$ gravida & 17 & 21.25 \\
\hline & $3^{\text {rd }}$ gravida & 10 & 12.5 \\
\hline & $4^{\text {th }}$ gravida & 6 & 7.5 \\
\hline & Grand multi & 3 & 3.75 \\
\hline \multirow{2}{*}{$\begin{array}{l}\text { Past history of obstetrics cholistasis among } \\
\text { multi parous women }\end{array}$} & Present & 22 & 61.1 \\
\hline & Absent & 14 & 38.88 \\
\hline \multirow{4}{*}{ Gestational age at the diagnosis } & $<28$ weeks & 9 & 11.25 \\
\hline & 28-32 weeks & 42 & 52.5 \\
\hline & 32-36 weeks & 25 & 31.25 \\
\hline & $>36$ weeks & 4 & 5.0 \\
\hline \multirow{3}{*}{ Mode of termination } & Spontaneous & 45 & 56.25 \\
\hline & Induced & 15 & 18.75 \\
\hline & Elective caesarean section & 20 & 25.0 \\
\hline \multirow{2}{*}{ Pregnancy outcome in spontaneous group } & Vaginal delivery & 35 & 77.77 \\
\hline & Caesarean section & 10 & 22.22 \\
\hline \multirow{2}{*}{ Pregnancy outcome in Induced group } & Vaginal delivery & 10 & 66.66 \\
\hline & Caesarean section & 05 & 33.33 \\
\hline
\end{tabular}

Table 3: Clinical and biochemical profile.

\begin{tabular}{|c|c|c|c|}
\hline Factors & & No. & Percentage \\
\hline \multirow{4}{*}{ Symptoms } & Pruritus & 72 & 90.0 \\
\hline & Sleep disturbances & 33 & 41.25 \\
\hline & Vomiting & 12 & 15.0 \\
\hline & $\begin{array}{l}\text { Yellowish } \\
\text { discolouration of } \\
\text { sclera }\end{array}$ & 5 & 6.25 \\
\hline \multirow{4}{*}{$\begin{array}{l}\text { Serum } \\
\text { billirubin } \\
\text { (mg/dl) }\end{array}$} & $0.2-0.8$ & 24 & 30.0 \\
\hline & $0.9-1.6$ & 36 & 45.0 \\
\hline & $1.7-3.2$ & 15 & 18.75 \\
\hline & $3.3-4.8$ & 5 & 6.25 \\
\hline AST (IU/I) & $<30$ & 2 & 2.5 \\
\hline \multirow{3}{*}{ AST (IU/I) } & $30-100$ & 15 & 18.75 \\
\hline & $101-300$ & 36 & 45.0 \\
\hline & $301-600$ & 27 & 33.7 \\
\hline ALT (IU/I) & $<30$ & 2 & 2.5 \\
\hline \multirow{3}{*}{ ALT (IU/I) } & $30-100$ & 18 & 22.5 \\
\hline & $101-300$ & 32 & 40.0 \\
\hline & $301-600$ & 28 & 35.0 \\
\hline \multirow{3}{*}{$\begin{array}{l}\text { Serum ALP } \\
\text { (IU/I) }\end{array}$} & $200-400$ & 26 & 32.5 \\
\hline & $401-600$ & 31 & 38.75 \\
\hline & $601-800$ & 23 & 28.75 \\
\hline
\end{tabular}

Table 4: Complications of pregnancy.

\begin{tabular}{|lll|}
\hline Complications & No. & Percentage \\
\hline Total CS & 35 & 43.75 \\
\hline PPH & 11 & 13.75 \\
\hline PPROM & 09 & 11.25 \\
\hline Preterm labour & 20 & 25 \\
\hline Deranged coagulation profile & 5 & 6.25 \\
\hline
\end{tabular}

There were various maternal complications occurred in women of Obstetric cholestasis but more commonly seen were preterm labour (25\%), post-partum haemorrhage $(13.75 \%)$ and preterm pre mature rupture of membrane (11.25\%) (Table 4).

Table 5: Perinatal outcomes.

\begin{tabular}{|lll|}
\hline Complications & Number & Percentage \\
\hline Meconium aspiration & 16 & 20 \\
\hline Pre-term birth & 24 & 30 \\
\hline Low birth weight & 28 & 35 \\
\hline Fetal distress & 15 & 18.75 \\
\hline NICU admission & 35 & 43.75 \\
\hline IUFD & 2 & 2.5 \\
\hline Neonatal death & 0 & 0 \\
\hline
\end{tabular}

Perinatal outcome revealed meconium aspiration (20\%), preterm birth $(30 \%)$, low birth weight $(35 \%)$, fetal distress (18.75\%) and intrauterine fetal death (2.5\%). $43.75 \%$ neonates required NICU admission and there were no neonatal death seen in our study (Table 5).

Table 6: Post-partum resolution after 6 weeks of delivery.

\begin{tabular}{|llll|}
\hline Factors & & No. & Percentage \\
\hline \multirow{2}{*}{ LFT } & Normal & 76 & 95 \\
\cline { 2 - 4 } & Raised & 4 & 5 \\
\hline \multirow{2}{*}{ Symptoms } & Relieved & 80 & 100 \\
\cline { 2 - 4 } & Not relieved & 0 & 0 \\
\hline
\end{tabular}

Liver function test returned to normal in $95 \%$ patients and $100 \%$ women became symptom free after 6 weeks postpartum (Table 6). 


\section{DISCUSSION}

Prevalence of obstetric cholestasis is influenced by genetic and environmental factors and varies between populations worldwide. In England, obstetric cholestasis affects $0.7 \%$ of pregnancies in multiethnic populations and $1.2-1.5 \%$ of women of Indian-Asian and PakistaniAsian origin. In Chile, $2.4 \%$ of all pregnancies are affected with $5 \%$ prevalence in women of AraucanianIndian origin. ${ }^{6}$ The incidence of obstetric cholestasis among Indian women has been reported as about $1 \% .4,5$ We found an incidence of $1.9 \%$ in our study. Here it is wise to mention that our hospital is a tertiary care hospital in this region and is main referral center for 6-7 adjoining district of Uttar Pradesh and Bihar. The incidence of high risk pregnancy is higher in our hospital. Hence, the incidence of obstetric cholestasis is expected to be higher than that in the community.

Heinonen et al reported that women of relatively advanced age (over 35 years) were at increased risk of developing intrahepatic cholestasis. ${ }^{7}$ However, maternal mean age in our study was $27.81 \pm 3.65$ years (range $20-35$ years) and this is consistent with other studies. ${ }^{8,9}$

Obstetric cholestasis occurs most commonly is primigravida and it tends to recur in subsequent pregnancies upto $60-70 \% .^{5,8,9}$ In present study, $55 \%$ women were primigravida and recurrence rate was $61.1 \%$.

$80-96 \%$ of women presented after 30 completed weeks of pregnancy. ${ }^{4,5,8,10}$ Similarly in our study, obstetric cholestasis was diagnosed in third trimester in $88.7 \%$ women. Generalised pruritus was the most common symptom $(90 \%)$ and was most pronounced in palm and soles. It has been reported that severe pruritus of sole of feet may be particularly suggestive of this condition. ${ }^{5}$ However, it has been reported in upto $10 \%$ of women. ${ }^{11}$

Unexplained abnormalities in one or more of the transaminases, GGT (gamma glutamyl transferase) and/or bile salts are consistent with a diagnosis of obstetric cholestasis. The most commonly elevated liver function test have been reported as transaminases and total bile acids. And typically the transaminases range from just normal to several hundreds ${ }^{6}$. In the present study, transaminases were raised in more than $97 \%$ cases in the range of 30-600 mIU. Five women with generalised pruritus initially presented with normal transaminase levels. On repeat liver function test after one to two weeks, transaminases were found to be elevated. It has been reported that itching may be present either before or after abnormal liver function test is detected and this may reflect the heterogenous nature of the condition. ${ }^{1}$ In contrast to other studies like Padmaja et al and Sharma et al who reported raised serum bilirubin in $18.4 \%$ and $40 \%$ respectively, we found it in $70.2 \%$ (56) cases and out of these, $64.2 \%$ (36) women had Serum bilirubin in the range of $0.9-1.6 \mathrm{mg} / \mathrm{dl} .{ }^{8,9}$
There is an increased risk of delivery by caesarean section (25.9-36\%). Though it is not clear whether the high rates are due to active management or because of complications as a result of disease or both. Overall vaginal delivery versus caesarean section rate in our study was $56.25 \%$ versus $43.75 \%$ while Rook et al reported $84 \%$ versus $14.9 \% .^{12}$ Caesarean section rate $(43.75 \%)$ in our study was high. Actually overall Caesarean section rate in our hospital itself is high in order to higher incidence of complicated pregnancy. The prevalence of normal vaginal delivery was higher in women where labour started spontaneously. Most common indication for caesarean section were fetal distress and non-progression of labour.

Kenyon et al found a high incidence of postpartum haemorrhage in women with obstetric cholestasis who did not receive vitamin $\mathrm{K}$ compared to those who did ( $45 \%$ versus $12 \%) .{ }^{4}$ In the present study, women did not receive vitamin $\mathrm{K}$ and postpartum haemorrhage occurred in $13.75 \%$ women. There was no case of PPH reported by Sharma et al and Padmaja et al. ${ }^{8,9}$ We found preterm labour and PPROM in $25 \%$ and $11.25 \%$ respectively which is very similar to Padmaja et al i.e. $24 \%$ and $8.9 \%{ }^{9}$

Intrahepatic cholestasis of pregnancy has been associated with increased risk of preterm delivery (upto 60\%), meconium staining of amniotic fluid (upto 27\%) fetal bradycardia (upto 14\%), fetal distress (22-41\%) and fetal loss (0.4-4.1\%) particularly when serum bile-acid level goes beyond $40 \mathrm{mmol} / \mathrm{L} .^{7,13-15}$ In the present study, we found premature delivery (spontaneous and iatrogenic), meconium staining, low birth weight babies and fetal distress in $30 \%, 20 \%, 35 \%$ and $18.75 \%$ neonates respectively. Although there was no neonatal death but unfortunately two stillbirth $(2.5 \%)$ occurred in our study at 35 and 36 weeks of gestation. Women having Intrauterine fetal demise (IUFD) had normal AFI (amniotic fluid index), CTG (cardiotocography) tracing and Doppler 12 hour prior to the detection of fetal death. No other pregnancy complication was seen in the mother. Fetus was grossly normal. Cause of intrauterine fetal demise (IUFD) may be due to acute anoxic event due to direct cardiotoxic effect of bile acid or vasoconstriction of placental vessels. ${ }^{16}$ In the present study, we could not measure bile acid in these women. However, transaminase levels were 20 times (500-600 IU/l) more than normal. There was data relating to prediction of fetal death and liver enzyme concentration which showed more fetal distress with high alanine amino transferase level. It has been reported that higher bile acid level ( $>40$ $\mathrm{mmol} / \mathrm{l})$ is associated with higher preterm delivery, fetal death, passage of meconium and abnormal CTG. ${ }^{13-15}$

All women with obstetric cholestasis were prescribed with ursodeoxycholic acid (UDCA) $20 \mathrm{mg} / \mathrm{kg} /$ day in the present study. Apart from reducing pruritus as well as improving biochemical parameters, various perinatal complications like preterm labour, fetal distress, meconium staining of liquor were less. It may be due to 
early pharmacological intervention in the form of ursodeoxycholic acid in all cases. Although, the mechanism of action is not fully understood, it has been postulated that ursodeoxycholic acid works by displacing hydrophobic endogenous bile salts from their toxic effects and enhancing bile acid clearance across the placenta from fetus. ${ }^{6}$

The risk of fetal death increases near term and most death occur after 37-38 weeks. To avoid the risk of fetal death, many hospitals adopt a policy of active management with anti natal surveillance and elective delivery at 37-38 weeks. In our study, active management including intensive fetus surveillance with delivery between 37-38 completed weeks of gestation was used.

Our study has certain limitations also. Firstly it was an observational study had no control group. A wellorganized randomized controlled trials of available therapies and fetal survillance scheme are required.

Another weakness lies in the fact that it measure the incidence of obstetric cholestasis at tertiary care institute and not in the general population. It should be carried out at multiple centers so we can have large number of patients to find out the possible reduction in perinatal mortality.

\section{CONCLUSION}

The incidence of obstetric cholestasis is high in our hospital, a tertiary care institute. Obstetric cholestasis usually presents in third trimester of pregnancy with pruritus as a cardinal symptom and has high recurrence in future pregnancy. Cholestasis of pregnancy has an adverse effect on the fetal outcome and hence early diagnosis with careful clinical examination and biochemical testing is essential. Serum abnormality in liver function test (transaminases) tended to be higher in women with poor perinatal outcome. Affected women should be offered treatment with ursodeoxycholic acid

Further randomized control trial of early versus spontaneous delivery may be justified

Funding: No funding sources

Conflict of interest: None declared

Ethical approval: The study was approved by the Institutional Ethics Committee

\section{REFERENCES}

1. Kenyon AP, Piercy CN, Girling J. Pruritus may precede abnormal liver function tests in pregnant women with women with obstetrics cholestasis: a longitudinal analysis. BJOG. 2001;108(11):1190-2.
2. Wei J, Wang H, Yang X, Dong M, Wang Z. Altered gene profile of placenta from women with intrahepatic cholestasis of pregnancy. Archives of gynecology and obstetrics. 2010;281(5):801-10.

3. Arrese M, Reyes H. Intrahepatic cholestatsis of pregnancy : a past and present riddle. Ann Heptol. 2010;5:202-5.

4. Kenyon AP, Piercy CN, Girling J, Williamson C, Tribe RM, Shennan AH. Obstetrics cholestasis, outcome with active management: a series of 70 cases. BJOG. 2002;109:282-8.

5. Ray A, Tata RJ, Balsara R. Cholestatsis of pregnancy. J Obstet Gynecol India. 2005;55:247-50.

6. Royal college of obstetricians and gynaecologists. Obstetrics cholestatsis. RCOG Green-top guideline No. 43; 2011.

7. Heinonen S, Kirkinen P. Pregnancy outcome with intrahepatic cholestasis. Obstet Gynecol. 1999;94:189-93.

8. Sharma N, Panda S, Singh AS. Obstetric outcome during an era of active management for obstetrics cholestatsis. J Obstet Gynecol India. 2016;66(1):3841.

9. Padmja M, Bhaskar P, Gupta JK, Seetha R, Mahasweta C. A study of obstetric cholestatsis. J Obstet Gynecol India. 2010;60(3):225-31.

10. Reyes H, Radrigan ME, Gonzalez MC. Steatorrhea in patients with intrahepatic cholestasis of pregnancy. Gastroenterology. 1987;93(3):584-90.

11. Rioseco AJ, Ivankovic MB, Manzur A. Intrahepatic cholestasis of pregnancy:A retrospective case control study of perinatal outcome. Am J Obstet Gynecol. 1994;170:890-5.

12. Rook M, Vargas J, Caughey A, Bacchetti P, Rosenthal P, Bull L. Fetal outcomes in pregnancies complicated by intrahepatic cholestasis of pregnancy in a Northern California cohort. Plos One. 2012;7(3):e28343.

13. Williamson C, Hems LM, Goulis DG, Walker I, Chambers J, Donaldson O, et al. Clinical outcome in a series of cases of obstetric cholestasis identified via a patient support group. BJOG. 2004;111(7):676-81.

14. Pata O, Vardarelli E, Ozcan A. Intrahepatic cholestasis of pregnancy: correlation of preterm delivery with bile acids. Turk J Gastroenterol. 2011;22(6):602-605.

15. Glantz A, Marschall HU, Mattsson LA. Intrahepatic cholestatsis of pregnancy: relationship between bile acid levels and fetal complication rates. Hepatology. 2004;40:476-474.

16. Greenes V, Willamson C. Intrahepatic cholestasis of pregnancy. World J Gastroenterol. 2009;15(17):2049-66.

Cite this article as: Anand RS, Khan N, Malik N, Aditya V, Singh R. Maternal and perinatal outcome in obstetric cholestasis- a prospective observational study. Int J Reprod Contracept Obstet Gynecol 2021;10:653-7. 